\title{
Las palabras del mal en el Poema de mio Cid
}

\section{(The Words of Evil in the Poema de mio Cid)}

\author{
MARTA LACOMBA \\ mlacomba07@gmail.com \\ Université Bordeaux Montaigne
}

Fecha de recepción: 28 de octubre de 2019

Fecha de aceptación: 12 de marzo de 2020

Resumen: En este estudio se analizan todas las ocurrencias del término "mal" en el Poema de mio Cid. A partir de este trabajo, en un primer tiempo léxico, que permite establecer la profunda coherencia de la obra en cuanto al uso del adjetivo, adverbio y sustantivo "mal", se trata de relacionar esta temática no solo con la caracterización de los personajes sino tanto con la noción de revelación y verdad como con la articulación de un sistema de poder.

Palabras clave: Épica medieval. Héroe. Mal. Verdad. Análisis léxico. Coherencia poética.

\begin{abstract}
This work analyses all occurrences of the term "mal" in the Poema de mio Cid. That first lexical study allows to establish the profound coherence of the work in terms of the use of the adjective, adverb and noun "mal". The problem will be, then, to relate this theme not only to the characterization of the different groups of persons, but also with the notion of revelation and truth as well as to the articulation of a system of power.
\end{abstract}

Keywords: Medieval Epic. Hero. Evil. Truth. Lexical Analysis. Poetic Coherence.

El cristianismo occidental, en el que por fuerza se inscriben las coordenadas no solo del Poema de mio Cid sino de gran parte de la literatura hispana, concibe el mal como la ausencia o la negación del bien. El mismo señor de los infiernos, Lucifer, no es sino un ángel "caído" que, al rebelarse -es decir al apartarse del bien-, es expulsado de los cielos. El mal está pues asociado a la falta, al castigo, a la exclusión y a la pérdida, como lo indica el topos del "Paraíso perdido", que 


\section{MARTA LACOMBA}

da título a la obra de Milton. Del bien se piensa pues que existe -o fue creadoper se, mientras que el mal sería una desviación del camino recto, o en palabras de Dante, de la diritta via ${ }^{1}$. Tanto Lucifer, como después Adán y Eva, eligen apartarse del bien, y como castigo, serán física y espacialmente excluidos del lugar del bien, del reino de los cielos y del jardín del edén respectivamente. La noción del mal resulta pues inseparable de la del castigo, que conlleva la exclusión moral y espacial. En esta tradición se inscribe el Poema de Mio Cid, obra en la cual los villanos infantes de Carrión, tras actuar mal y recibir el dictamen de "traidores", serán por ende excluidos. Esta exclusión no será espacial, ya que no serán enviados a ninguna cárcel física, sino social. Al ser declarados "infames" se convertirán, como vamos a ver, en unos apestados, unos muertos vivientes sociales.

La maldad irrumpe en el Poema de mio Cid (PMC a partir de ahora) ya en sus primerísimos versos, en los que el héroe al tomar la palabra designa a unos "enemigos malos", responsables de sus desdichas, de ser injustamente víctima de la ira regia, y por ende castigado con el exilio². Queda pues claro desde un principio que el trasfondo del asunto es moral y político, y que el rey anda equivocado sobre a quienes otorga su confianza. Mi propósito es tratar de determinar cómo se encarna ese mal, con qué palabras, qué tipo de poética épica se configura, es decir cómo se nombra, cómo se caracteriza y cómo se denuncia el mal.

He partido para ello del texto, y más concretamente del análisis exhaustivo de las 69 ocurrencias de "mal" en el PMC3. "Mal" puede ser adjetivo, adverbio o sustantivo: mi trabajo se estructurará en torno a estas tres categorías gramaticales ya que, como espero demostrar, ello resulta pertinente para proponer un eje de lectura. La primera parte estará pues dedicada al mal adjetival, aquel que califica o determina a un sustantivo. En la segunda parte trataré el mal como adverbio, que proporciona información sobre la manera en que se realizan ciertas acciones o se modifican ciertos adjetivos. Terminaré, en una tercera parte, analizando el mal como sustantivo, encarnado pues en seres o entidades.

\footnotetext{
1 "Nel mezzo del cammin di nostra vita // mi ritrovai per una selva oscura, // ché la diritta via era smarrita". Dante no se refiere aquí explícitamente al infierno, pero sí al camino que lo va a conducir a él.

${ }^{2}$ En lo referente a la causa del destierro, los enemigos de Rodrigo Díaz de Vivar lo acusaron de haberse quedado con parte del tributo que los musulmanes debían entregar al rey Alfonso VI, como se descubre en los versos 109-115.

${ }^{3}$ Véase Pellen 1979: 145.
} 
Las palabras del mal en el Poema de mio Cid

\section{El "mal" adjetival}

La razón para comenzar por el estudio de las ocurrencias de "mal" como adjetivo es doble. Primero, por motivos etimológicos: cabe recordar que, tanto en castellano como en latín, "mal" es originalmente adjetivo "malo", o "malus", del que se derivan a través de la apócope, tanto el sustantivo como el adverbio. La segunda razón es discursiva: la primera ocurrencia de "mal" en el Poema de mio Cid es adjetival, y aparece ya en el verso 9: "Esto me an buelto mios enemigos malos!"4.

\subsection{Los "enemigos malos"}

Esta primera ocurrencia es crucial, puesto que sienta la frontera y la significación de la obra: el Cid tiene enemigos, personales, como lo demuestra el uso del adjetivo posesivo "mis", y si estos se sitúan en el campo del mal, ello significa que el Cid representa el campo del bien. Ahora bien, el mal, que encarnan estos "enemigos malos" no reviste un carácter absoluto, sino que se circunscribe, por el contrario, a un aquí y ahora muy concretos ${ }^{5}$. Apoyan y refuerzan la crucialidad de esta ocurrencia dos elementos concatenados. Primero, "malo" se encuentra aquí postpuesto al sustantivo; y segundo, al ser el último término de la frase queda por ello acentuado, al recaer sobre él la rima (en "á-o", que se inicia en el verso 1). Se trata además de la última palabra de la tirada primera, ya que en el verso 10 se inicia una nueva y breve tirada en "é-a". Por otro lado, es necesario señalar que "malo" no hace sino reforzar el sentido negativo del sustantivo al que acompaña, "enemigo". Como último punto sobre esta primera ocurrencia, es necesario señalar que esos "enemigos malos" por ahora no tienen nombre.

\footnotetext{
${ }^{4}$ Verso 9 (ed. Montaner 1993: 103); todas las citas proceden de esta edición; a partir de ahora, se consignará pues únicamente el/los número/s de verso/s.

${ }^{5}$ Esto nada tiene que ver con lo que ocurre por ejemplo en el Poema de Fernán Gonqález, obra marcada por "la demonización total y absoluta del "otro" (Nuñez González 2004). La lucha contra los musulmanes tiene en el $P M C$ un cariz eminentemente territorial, marcado por las vicisitudes históricas; "el aspecto tipológico del poema va más allá del héroe: la lucha de España, y sobre todo de Castilla, contra los moros se concibe dentro de la perspectiva histórica cristiana, en la cual la historia humana sigue el plan divino, y se explica en términos de pecado y redención" (Deyermond 1987: 73-74).

${ }^{6} \mathrm{El}$ adjetivo "malo" tiene un peso nocional esencial en la mentalidad medieval: "Resulta más fácil hipostatizar las nociones que poseen una amplia valencia semántica para un número máximo de los objetos de la realidad. En el campo de la calificación son las características más abstractas: bueno/malo, grande/pequeño. A fin de cuentas, estos cuatro conceptos son suficientes para dar una característica calificativa abstracta de todos los objetos del mundo real" (Zernova 2015: 523).
} 


\section{MARTA LACOMBA}

Veamos ahora qué ocurre con las demás ocurrencias en las que "malo" sirve ante todo para hacer peores a los enemigos del $\mathrm{Cid}^{7}$. La siguiente ocurrencia del adjetivo "malo" para definir a los enemigos del Cid, aún sin nombre ni rostro, se encuentra en boca de Jimena, su esposa: "iMerced, Canpeador, en buen hora fuestes nado! / Por malos mestureros de tierra sodes echado" (266-267). Como ya ocurría en el verso 9, es de destacar la antítesis entre el bien, que se encuentra por supuesto del lado del Cid, y que se expresa aquí bajo la forma laudativa del epíteto épico "en buen hora fuestes nado" del segundo hemistiquio del verso 266. En la tercera ocurrencia en la que "malo" designa a los enemigos del héroe, se produce una novedad: ya no se trata de un plural, sino de un singular, y de un singular que designa a un personaje identificado y conocido. La voz poética designa en efecto al conde don García de Cabra como "enemigo malo" (1836) ${ }^{8}$.

Dejando por ahora de lado la cuestión de la identificación, sobre la que volveré más adelante, cabe destacar que el adjetivo "malo", con valor calificativo, produce en estas tres ocurrencias la intensificación del carácter negativo del sustantivo "enemigo" o "mesturero".

\section{2. "Malo" discrimina a sustantivos sin carga negativa}

Me centraré ahora en el segundo grupo de ocurrencias del adjetivo "malo" que, al contrario de lo que ocurre con "enemigos" o "mestureros", no califica a sustantivos ya de por sí negativos. En este caso, al tratarse de términos que podrían calificarse como neutros, puesto que pueden ser "buenos" o "malos", el adjetivo cumple un papel de especificación y discriminación.

Lo notable es que todas estas ocurrencias en las que, insisto, "malo" caracteriza a un sustantivo sin carga, a priori, negativa, se refieren a los infantes de Carrión. Esto se produce en tres ocasiones. En el cantar tercero, durante el episodio del Robledo de Corpes, frente a los infantes dispuestos a golpearlas, las hijas del Cid les piden que: "Atán malos ensiemplos non fagades sobre nós”"10. En este mismo episodio, a pesar de los ruegos de las hijas del Cid, los de

\footnotetext{
${ }^{7}$ No se tratarán las ocurrencias por orden de aparición, sino en función de su sentido.

${ }^{8}$ El adjetivo "malo" equivale aquí a "malvado" (Montaner 1993: 214, nota 1836).

9 Es necesario precisar que algunas ocurrencias de "malo", cuatro para ser exacta, intensifican también características ya negativas de un substantivo: "mala cárcel" (340), "mala cueta" (1178), "vergüenzas malas" (1596) y "mala sobrevienta" (2282). Pero al no tratarse de una descalificación moral ni referirse a ningún personaje, no han sido tenidas en cuenta para este trabajo. Tampoco contemplaré las ocurrencias de la expresión lexicalizada "dinero malo", que se repite en tres ocasiones (en los versos 165, 503 y 1042) con el sentido de ningún o muy poco dinero.

10 "Malos ensiemplos" debe entenderse aquí "grandes crueldades" (Montaner 1993: 265, nota 2731).
} 
Carrión empiezan a golpearlas "con las espuelas agudas, don ellas an mal sabor" (o "gran disgusto") 11 . La última ocurrencia del adjetivo "malo" con peso discriminador y directamente relacionada con las acciones de los infantes, se encuentra también en el cantar tercero, durante los preparativos para las lides: los infantes y sus parientes llegan a Carrión, donde deben celebrarse las lides judiciales, y planean un ataque a la tropa cidiana. Este malvado plan no llega sin embargo a ponerse en práctica: "El cometer fue malo, que lo ál no s'enpeçó" (3542). Como ya se ha precisado, "ejemplo", "sabor" y "cometer" son sustantivos que no poseen de por sí una carga negativa. Ello significa que, si las acciones en las que están involucrados estos sustantivos resultan malas, y no buenas, se debe a la elección de sus sujetos. Los infantes eligen pues hacer el mal en vez del bien.

A estas de ocurrencias en las que el sustantivo al que acompaña "malo" no tiene en sí carga negativa, y caracteriza acciones emprendidas por los infantes de Carrión, hay que añadir tres más, que van a permitirnos afinar el sentido de las anteriores. La primera ocurrencia se encuentra tras la agresión del Robledo de Corpes. Cuando por fin encuentra a sus primas, Félez Muñoz les dice, refiriéndose a los infantes: "A Dios plega e a Santa María que dent prendan ellos mal galardón!” (2782). El galardón -que puede ser bueno, y sería entonces un premio o recompensa- es aquí "malo", es decir un castigo" ${ }^{12}$. Obviamente, la mala actuación de los infantes, anteriormente descrita, provoca en los personajes de la esfera cidiana (así como en la voz poética y en el receptor) el deseo de que se imparta justicia. Haciéndose Félez Muñoz portavoz de este deseo, formula, situándola lógicamente en un futuro, la única consecuencia del mal hacer de los esposos de las hijas del Cid que se puede contemplar, es decir que sean castigados. Tras la temática del mal despunta ya la cuestión de la justicia.

Al saber lo ocurrido en el Robledo de Corpes, el Cid reclama al rey la celebración de unas cortes. En ese marco, tras la devolución de los bienes entregados por el héroe a sus yernos, los caballeros del Cid desafían a los infantes. El primero en tomar la palabra es Pero Vermúez que, entre otras cosas, llama a Fernando de Carrión "mal varragán” (3327), que debe entenderse aquí como cobarde ${ }^{13}$. Sus acciones no son pues las que corresponden a un noble. Las cortes son el ámbito en el cual la maldad de los infantes deja de ser secreta y privada para convertirse en asunto público. Como es sabido, se

11 Idem: 266, nota 2737.

12 El Cid les promete a sus yernos "buen galardón" (2582), es decir una recompensa, si sirven bien a sus hijas.

${ }^{13}$ Sobre las particularidades de este personaje épico, véase Janín (2007). 


\section{MARTA LACOMBA}

produce justicia, y el deseo del clan cidiano de que los infantes se lleven un "mal galardón" se cumple. Así pues, el "mal sabor" sufrido por las hijas del héroe será en última instancia para ellos, como rezan los versos finales:

Dexémosnos de pleitos de ifantes de Carrión, de lo que an preso mucho an mal sabor; fablemos nós d'aqueste que en buen ora nació [...] (3708-3710).

Se produce de esta manera un contraste moral, entre el bien y el mal, entre el "mal sabor" merecido de los infantes y la "buen ora" del nacimiento del héroe. Cabe señalar que, al contraste moral se suma un contraste temporal, clave para la interpretación de la obra: mientras que el epíteto astrológico ("el que en buen ora nació") caracteriza al Cid desde los primeros versos, la infamia de los infantes ha requerido ser revelada. Ahora bien, una vez que este mal hacer ha sido revelado y castigado, debe ser rápidamente olvidado. En efecto, como si de un mero problema se tratase, una vez resuelta $-\mathrm{y}$ disuelta, puesto que quedan sin margen de maniobra- la maldad de los infantes deja de ser una preocupación, como lo indica el verso 3708 ("Dexémosnos de pleitos"). Las malas acciones de los infantes no provocan encono, tan solo merecen olvido ${ }^{14}$.

\subsection{De los "enemigos malos" al "mal sabor" de los infantes de Carrión}

Para concluir esta primera parte es necesario destacar que se produce, con respecto al uso del adjetivo "malo", una evolución muy clara a lo largo de la obra. Se puede así establecer para el adjetivo malo tres categorías, que van sucediéndose y tomando la una el lugar de la otra, indicando la importancia no solo de la justicia, sino de la verdad.

La primera de estas categorías califica a los oponentes del Cid, pero no se refiere nunca de manera explícita a los infantes de Carrión. Aparece en el verso 9 y en el 267; en el verso 1836, como ya se dijo, es García de Cabra quien es tachado de "enemigo malo", deshaciéndose así en parte la nebulosa "enemigos malos", pero sin que los infantes sean por ahora señalados. En la segunda, determinativa y exclusivamente referida a los infantes esta vez nombrados, términos neutros como "sabor" (2731), "ejemplos" (2737), y "cometer" (3542), se convierten en malas acciones. De unos malvados sin rostro se pasa a unas

${ }^{14}$ En un texto como el Cantar de mio Cid, en el que el dinamismo prima sobre cualquier otro principio interno, no hay lugar para el regodeo melancólico. Es un poema sin spleen, donde la acción se impone jubilosa, y las desgracias resultan ante todo acicates para el Cid y los suyos [...] (Montaner 2007: 91). 
malas acciones con nombre y apellido. Por último, el tercer grupo de ocurrencias de "malo" revela que esa maldad ha sido por fin descubierta, hecha pública. De ahí el "mal galardón" anhelado (2782), el "mal barragán" (3327) proferido y, a la postre, el "mal sabor" merecido (3709). Queda todo ello resumido en el cuadro siguiente:

\begin{tabular}{|c|c|c|c|}
\hline & $\begin{array}{c}\text { No se nombra } \\
\text { explícitamente a los } \\
\text { infantes }\end{array}$ & $\begin{array}{c}\text { Actos de los } \\
\text { infantes } \\
\text { (anti-hazañas) }\end{array}$ & $\begin{array}{c}\text { Consecuencias } \\
\text { para los infantes }\end{array}$ \\
\hline $\begin{array}{c}\text { "Malo" intensifica } \\
\text { la maldad de } \\
\text { sustantivos } \\
\text { negativos }\end{array}$ & $\begin{array}{c}\text { - enemigos malos } \\
\text { - malos mestureros } \\
\text { - enemigo malo } \\
\text { (García de Cabra) }\end{array}$ & & \\
\hline $\begin{array}{c}\text { "Malo" revela la } \\
\text { elección de la } \\
\text { maldad }\end{array}$ & & $\begin{array}{c}\text { - malos ensiemplos } \\
\text { - mal sabor }\end{array}$ & $\begin{array}{c}\text { - mal galardón } \\
\text { - mal varragán } \\
\text { - mal sabor }\end{array}$ \\
\hline
\end{tabular}

Se puede por lo tanto establecer una evolución, incluso un relato, a través de las ocurrencias del adjetivo "malo": de la mención de unos malvados anónimos -evocadas tan solo a través de los efectos negativos que causan sus actos y que sufre el héroe-, se pasa a las acciones dañinas perpetradas por los infantes de Carrión, que irán seguidas de las consecuencias negativas que para ellos entraña la revelación de su vileza. El mal no es algo pues evidente, sino soterrado que se va desvelando y actualizando a lo largo de la obra.

\section{El adverbio "mal"}

Los adverbios modifican el sentido de otro adverbio, de un verbo o de un adjetivo. Se tratará por lo tanto de intentar encontrar pautas de utilización en la manera en que el mal adverbial altera otros términos. Como en el caso de los adjetivos, y como lo haré después para los sustantivos, he partido de un análisis exhaustivo de las ocurrencias, que procedo a agrupar en función de su sentido.

\subsection{De mal en peor}

El primer grupo queda conformado por las ocurrencias en las que "más" tiene valor intensificador, equivalente a "mucho" ante un verbo, o ponderativo, equivalente a "muy", ante un adjetivo ${ }^{15}$. Obviamente, estos valores de

15 Cabe señalar que el Diccionario de la Real Academia de la Lengua Española no recoge estas dos acepciones del adverbio "mal", que parecen en efecto haber desaparecido al menos en España, pero que, sin embargo, sí se contemplan para el adverbio "bien": adv. mucho (\| con mucha 


\section{MARTA LACOMBA}

intensificación o de ponderación del adverbio "mal" se dan cuando el verbo o el adjetivo modulado ya tiene de por sí un sentido negativo. En el PMC, se trata de "mal pesar", "mal aquexarse", "mal escarmentar" y "mal traer"16. Con esta última expresión, la voz poética indica que el héroe está teniendo éxito en sus campañas en tierras no cristianas, y por lo tanto "maltrayendo", maltratando a sus habitantes: "Fueron los mandados a todas partes/ que el salido de Castilla así los trae tan mal" (954-955). Las cuatro ocurrencias de "mal pesar" se refieren al sentir de los antagonistas musulmanes del Cid, en el ámbito de la conquista territorial que este lleva a cabo al abandonar Castilla ${ }^{17}$. Lo mismo ocurre con "mal aquexarse", que alude al sufrimiento de los habitantes de la Valencia sitiada por las tropas cidianas: "Mal se aquexan los de Valencia, que no sabent qué s' far" (1174). En cuanto a los "mal escarmentados", se trata de los infantes de Carrión, que sufren las burlas de los hombres del Cid" ${ }^{18}$.

En esta primera categoría, el "mal hacer" cobra por lo tanto un sentido positivo para el bando cidiano. En efecto, al describir las ocurrencias de "mal pesar", "mal aquexarse" y "mal traer" el padecimiento de los musulmanes de los territorios conquistados por el héroe, ya sea de Teca, Xátiva o Valencia, ello implica la exaltación de las cualidades guerreras de quien es capaz de provocar dicho padecimiento ${ }^{19}$.

\section{2. "Mal" hacer como elección}

El segundo grupo del mal adverbial está formado por ocurrencias en las que "mal" tiene un sentido más pleno. En estos casos "mal" no se limita a

intensidad). Hoy ha llovido bien. // adv. ponder. antepuesto a un adjetivo o adverbio, muy. Bien tarde. Bien rico. Bien malo. Información disponible en: https://dle.rae.es/?id=5TkGdE0.

${ }^{16}$ No tendré en cuenta la ocurrencia del verso 3641 "mal ferido es de muert" por tratarse de una expresión casi lexicalizada.

${ }_{17}$ Se trata de los versos 625-626 Mucho pesa a los de Teca, e a los de Terrer non plaze,/ e a los Calatayut non plaze), 636 (Cuando lo oyó el rey Tamín por cuer le pesó mal) y 1164-1165: (Cuando el Cid Campeador ovo a Peña Cabdiella/ mal les pesa en Xátiva e dentro de Gujera). Tras la petición de matrimonio por parte de los herederos de Navarra y de Aragón, el Cid se dirige a los infantes: "Antes las aviedes parejas pora en braços amas a dos, /agora besades sus manos e llamarlas hedes señoras, / averlas hedes a servir mal que vos pese a vos" (3449-3451). En estos versos, el valor de "mal que" se asemeja al de la locución concesiva "por mal que", no tiene el sentido de "mal pesar" y por lo tanto no entrará dentro de este estudio. Véase Elvira 2003: 23 , nota 6 .

18 Por su mal comportamiento en situaciones de peligro, los hombres del Cid se mofan de los infantes: "Por aquesto juegos que ivan levantando / e las noches e los días tan mal los escarmentando [...]" (2535-2536).

19 "Mal escarmentar" también tiene como sujeto a los hombres del Cid y por objeto a sus antagonistas, pero en este caso de trata de los infantes de Carrión, y no de los musulmanes. 
intensificar el valor del término al que acompaña, sino que modifica el significado de verbos y adjetivos que no tienen de por sí sentido negativo. Es decir que lo desacertado de las acciones realizadas no recae, como en el caso anterior, en los verbos o los adjetivos, que se veían tan solo reforzados, sino en el propio adverbio "mal".

Un primer subconjunto, dentro de esta categoría, está formado por dos ocurrencias de "mal parecer", que aparece siempre en frases negativas, y viene por lo tanto a significar lo contrario, es decir "lucirse". El segundo subgrupo lo constituyen las expresiones de "mal tratar", "mal cumplir", "mal aconsejarse", "mal ensayar" y "mal jugar". Se trata de verbos que pueden llevar a buenas acciones o a malas, y su sentido va en este caso indicado por el adverbio.

\subsection{Diferentes maneras de "bacer mal"}

Ahora bien, para revelar la coherencia del $P M C$ en el uso y la distribución de las expresiones en las que el adverbio "mal" determina el sentido del verbo, es necesario referirlas a los personajes implicados. Se observa así que ambas ocurrencias de "no mal parecer" describen la ostentación y el lucimiento de las comitivas que acompañan a la familia del Cid de camino a Valencia. La primera sale de Burgos -el bueno de Minaya pensólas de adobar/ de los mejores uarnimientos que en Burgos pudo fallar,/ palafrés e mulas que non parescan mal (426-428)- y la segunda es la escolta enviada por el Cid desde Valencia, "ciento que non parecen mal" (1507), que se suma a la primera. El "non parecer mal" describe pues la honra visible de la familia del héroe. Honra que traduce el éxito del Cid tanto en sus campañas militares como en el restablecimiento de sus relaciones con el rey.

En cuanto al grupo de verbos que describen acciones que se realizan "mal", se constata la misma coherencia: todos ellos tienen como sujeto a los infantes de Carrión y dan cuenta de su descalificación moral. Así, para introducir el parlamento en el que estos proyectan maltratar "a las fijas del Campeador" (2551), la voz poética dice "tan mal se consejaron estos infantes amos" (2537). Cuando de camino a Carrión, tras una noche de amor, se anuncia la inminente desgracia de Corpes, la voz poética anuncia: "mal ge lo cumplieron cuando salié el sol" (2704). Ya tras la afrenta, al encontrar por fin a sus primas Félez Muñoz exclama: "Mal se ensayaron los ifantes de Carrión" (2781).

Se aprecia claramente que las ocurrencias del adverbio "mal" establecen que existen dos maneras de hacer el mal. Se puede hacer bien, como el Cid. Este va causando "mal pesar", "mal quejarse" o "maltrato" entre los habitantes de las tierras que conquista. Dicho de otro modo, este "mal hacer" significa que el héroe es un buen guerrero. Recuérdese que también "no parecer mal", 


\section{MARTA LACOMBA}

asimismo asociado al clan cidiano, tiene un carácter positivo. Se trata de hacer visible su posición ventajosa y honrosa ante los ojos de los demás.

Y el mal se puede hacer mal: los infantes cometen acciones que de por sí no son nefastas (aconsejarse, cumplir, ensayar) pero que con el adverbio "malo" cobran un sentido negativo. Es una manera de reforzar la maldad de los personajes, que eligen, pues, hacer el $\mathrm{mal}^{20}$. Y son advertidos ya en el mismo momento de actuar, por una de sus víctimas, de las consecuencias legales de estas malas acciones (Smith 1982: 237). Las palabras de doña Sol, una de las hijas del Cid, son clarísimas: "Si nos fueremos majadas, abiltaredes a vos, / retraer vos lo han en vistas o en cortes" (2732-2733).

\section{E1 mal sustantivo}

Veamos ahora qué ocurre con el mal sustantivo que, como todo sustantivo, y cito el Diccionario de la Real Academia, tiene "existencia real, independiente, individual"21.

\subsection{Maly poder}

La primera ocurrencia del mal sustantivo se sitúa en el primer cantar, durante el encuentro en Burgos entre el Cid y la niña de nueve años. Recuérdese que la niña le informa de que el rey ha prohibido a los habitantes de la ciudad que le abran la puerta al recién desterrado. Tras exponer las amenazas que pesan sobre los burgaleses, la niña concluye: "Cid, en nuestro mal vós no ganades nada" (47). Este verso resulta determinante. Instantes antes, el Cid había estado a punto de montar en cólera ante las puertas cerradas de Burgos, donde él esperaba un cálido recibimiento. La aparición de la niña impide a Rodrigo romper de una patada la puerta frente a la que se encuentra. Con su intervención, la niña le permite al Cid recobrar la mesura, y con su frase deja claro que el héroe está del lado del bien, puesto que no gana nada con el mal ajeno ${ }^{22}$. Cabe aquí destacar que, como lo anunciaba la niña, el Cid no provoca ese mal, no inflige ese sufrimiento a los habitantes de Burgos. Ahora bien, si no

20 La temática del mal resulta evidentemente indisociable de la noción de libre albedrío, igualmente capital en términos éticos, religiosos, filosóficos y legales, pero rebasa el ámbito de este estudio.

${ }^{21}$ Diccionario de la lengua española: "sustantivo, va. Tb. substantivo. 1. adj. Que tiene existencia real, independiente, individual".

$22 \mathrm{Si}$ el Cid "tras el brote de cólera que le lleva a patear la puerta de su posada burgalesa, [...], asume la situación"”, no cabe aquí sin embargo hablar de mera resignación u obediencia, sino que se trata de "lo que a justo título podrían denominarse estrategias de la obediencia" (Montaner 2011: 30). Estrategias que se pondrán en práctica más adelante, con las embajadas y los regalos al rey. 
lo hace, se entiende que bien hubiera podido, física y materialmente, hacerlo. Aflora por lo tanto la idea de que el mal tiene una relación con el poder, el poder de hacer el mal o, como en este caso, de no hacerlo.

La segunda, tercera y cuarta ocurrencia del mal sustantivo se encuentran en la plegaria de Jimena, cuando esta reza en San Pedro de Cardeña para que a su esposo no le suceda nada malo:

Echós' doña Ximena en los grados delant'el altar, rogando al Criador, cuanto ella mejor sabe, que a mio Cid el Campeador, que Dios le curiás de mal (327-329).

En su plegaria, Jimena nombra a varios hombres a los cuales Dios socorrió. Como Longinos, al que Dios devolvió la vista y "en ti crovo al ora, por end es salvo de mal" (357). El Cid aparece pues como otro eslabón de esta cadena, como otro merecedor de la protección y de la bondad divinas. La enumeración de milagros tiene por lo tanto como objetivo pedir a Dios que use su poder también en favor de Rodrigo Díaz:

Tú eres rey de los reyes e de tod el mundo padre, a ti adoro e creo de toda voluntad, e ruego a San Peidro que me ayude a rogar por mio Cid el Campeador que Dios le curie de mal (361-364).

Vuelve pues a aparecer la misma expresión que en el verso 329 "curar de mal", proteger, hacer bien. Cabe relacionar, a mi modo de ver, estas ocurrencias con lo ya señalado para el caso del Cid que, pudiendo hacerlo, elige no causar la desgracia de los habitantes de Burgos. Si Dios puede proteger al Cid del mal, de la desgracia, de la muerte, como ya lo hiciera en otros casos, es porque dispone de ese poder. De hecho, uno de los atributos de Dios es la omnipotencia, el ser todopoderoso. Así pues, tanto hacer el mal, o no hacerlo, como salvar a alguien de él, están relacionados con la noción de poder.

Corrobora esta idea la ocurrencia siguiente, en el verso 509. Tras la conquista de Castejón y Alcalá, en su primera campaña, el Cid teme las represalias del rey, por estar estos territorios bajo su protección, por ende bajo su poder: 
Comidiós' mio Cid, el que en buen ora cinxo espada, el rey Alfonso, que llegarién sus compañas, que 1' buscarié mal con todas sus mesnadas (507-509).

El rey puede "buscarle mal" al Cid, porque puede, porque tiene ese poder, y se justifica porque a sus ojos, el Cid ha incurrido en la ira regia.

Más adelante, se observa que también el Cid tiene la capacidad de causar daños a sus antagonistas. "Hacer mal" se convierte en este caso en el equivalente de ser buen guerrero, de hacer buen uso del poder de "hacer mal". Así pues, tras la caída de Alcocer, los mensajeros avisan al rey de Valencia de las hazañas cidianas y presagia que estas continuarán si este no pone remedio:

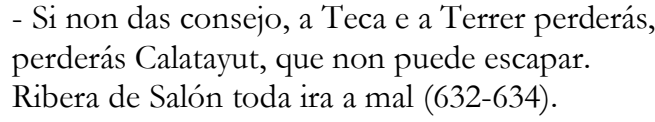
el Cid.

Lo que es un mal para el rey de Valencia, evidentemente sería un bien para

\subsection{Maly opinión}

Si el Cid tiene el poder de causar daño a sus antagonistas, también tiene la capacidad de modularlo, o de elegir cómo y cuándo ejercerlo. Tras la toma de Castejón, aparecen dos ocurrencias de "mal" sustantivo, con un sentido diferente del hasta ahora analizado:

Quitar quiero Castejón; oíd, escuelas e Minaya, lo que yo dixier non lo tengades a mal; en Castejón non podriemos fincar, [...] ciento moros e ciento moras quiérolas quitar, porque lo pris d'ellos, que de mí non digan mal (527-535).

Antes de examinar su significado, obsérvese que ambas ocurrencias de "mal" quedan subrayadas por ocupar la última posición del verso, es decir la más sonora, por ser la de la rima. En cuanto al sentido, no se trata aquí de un mal que el Cid podría llevar a cabo o no, sino de evitar que de sus actos se hable mal. Puesto que ambas proposiciones son negativas, cabe afirmar que el objetivo del Cid es que tanto sus hombres como los prisioneros moros tengan una buena opinión de él. 
Recapitulando lo que hasta ahora ha aportado el análisis del sustantivo "mal", en lo que al héroe se refiere, se observa, por un lado, que este dispone de un poder del que decide no hacer uso frente a la ciudad de Burgos atemorizada, pero que sí ejercita contra los territorios musulmanes; y, por otro, se revela que el Cid no quiere que se diga "mal" de él, y por lo tanto, cuida la manera en que usa ese poder tanto en la guerra como en la paz (al liberar a los prisioneros, que se encuentran en tierras del rey Alfonso). Así pues, las ocurrencias de mal sustantivo no nos llevan por ahora al campo de lo moral, sino al del poder y la diplomacia.

Tres ocurrencias resultan clave para poner de manifiesto esta relación entre "mal", poder y diplomacia. La primera es una frase en boca de Avengalbón, el señor de Molina, amigo y aliado musulmán del Cid, que, refiriéndose a este, le dice a Álvar Fáñez: “ondrarvos hemos todos, ca tal es la su auze, / maguer mal le queramos no ge lo podremos far" (1523-1524). El sentido de estos versos es "todos os honraremos pues su buena suerte es tanta/ que aunque le aborreciésemos, no podríamos hacerle daño" (Montaner 1993: 197)23. Queda bien claro que el Cid es el único que tiene la capacidad y por ende, el poder de ejercer el mal, tiene el monopolio de la violencia sobre las tierras por él dominadas.

La segunda ocurrencia se sitúa directamente en el ámbito de la diplomacia. En el segundo cantar, el rey termina reconociendo tanto el éxito de los esfuerzos desplegados por el héroe, de sus embajadas y regalos, como su error inicial: "Yo eché de tierra al buen Campeador / e faziendo yo a él mal e él a mî grand pro" (1890-1891)24. En estos versos se manifiestan dos elementos. El primero que las conquistas del héroe, y los consiguientes regalos al rey se engloban bajo el término "bien". El segundo punto que cabe destacar es que ese "hacer mal", según sus propias palabras, del rey al principio del cantar, resulta legítimo en tanto en cuanto se ejercía como represalia ante el supuesto "mal hacer" del Cid. Surge pues una cuestión importante, la del marco legal, exterior a los personajes, que delimita la frontera entre el buen "hacer mal" y el mal "hacer mal".

La tercera y última ocurrencia que muestra la relación entre "hacer mal", diplomacia y poder, aparece tras la batalla contra Búcar. Si bien el Cid y Minaya están felicitando sinceramente a los Infantes de Carrión por su comportamiento

23 “[...] nótese que mal se toma en esta frase a la vez como adverbio, que complementa a querer, y como sustantivo, sustituido por lo en la frase far mal, "dañar" (Montaner 1993: 197). Sobre el valor del término "auze", véase Montaner, 2007.

${ }^{24}$ Los regalos forman parte de una estrategia diplomática: "The Cid's gifts to Alfonso are not, then, merely an index of his generosity" (Duggan 1989: 33). 


\section{MARTA LACOMBA}

guerrero, estos se toman mal sus palabras: "Por bien lo dixo el Cid, mas ellos lo tovieron a mal" (2464). En este caso, el texto está dando a ver que la diplomacia no está funcionando: la clara oposición entre el "bien decir" del héroe y el "tomar a mal" de sus yernos muestra que los infantes no participan en este sistema de intercambios, y lo que es aún peor, no lo entienden ${ }^{25}$.

\subsection{Los actores de un sistema de poder}

Se confirma por lo tanto la relación entre hacer o no hacer el mal con la noción de poder, es decir de ejercicio de la violencia dentro de un marco considerado como legítimo, como la guerra o las represalias contra un enemigo. Paralelamente a estas manifestaciones directas del poder, se despliega toda una actividad destinada a enmarcarla, de manera que los demás actores políticos las descodifiquen correctamente y no vengan pues a "pensar mal". Para afinar esta interpretación es necesario prestar atención a quiénes ejercen o tienen el poder de ejercer el "mal" y quiénes desarrollan actividades diplomáticas, es decir quiénes son los actores de este sistema de poder.

El cuadro siguiente establece el sentido de las relaciones entre los personajes que actúan y son pues sujetos de poder y aquellos que resultan su objeto.

\begin{tabular}{|c|c|c|c|}
\hline & $\begin{array}{l}\text { No hacer mal } \\
\text { Protección } \\
\text { ejercida sobre: }\end{array}$ & $\begin{array}{c}\text { Hacer mal } \\
\text { Hostilidad legítima } \\
\text { ejercida sobre: }\end{array}$ & $\begin{array}{c}\text { Que no se piense mal } \\
\text { Diplomacia ejercida } \\
\text { sobre: }\end{array}$ \\
\hline Dios & $\begin{array}{c}\text { Cid } \\
\text { Jimena } \\
\text { Comitiva cidiana } \\
\text { hijas del Cid }\end{array}$ & & \\
\hline Rey & $\begin{array}{l}\text { - La familia del Cid } \\
\text { - Los hombres del Cid }\end{array}$ & El Cid & \\
\hline Cid & $\begin{array}{c}\text { Los habitantes de } \\
\text { Burgos }\end{array}$ & Los musulmanes & $\begin{array}{l}\text { - Los hombres del Cid } \\
\text { - Los habitantes de } \\
\text { Castejón } \\
\text { - El conde de Barcelona } \\
\text { - El rey } \\
\frac{\text { Fracaso de diplomacia: }}{\text { infantes }}\end{array}$ \\
\hline
\end{tabular}

Sujetos y objetos del sistema poder, protección y diplomacia

Como se puede apreciar, tan solo tres actores son los protagonistas activos de este cuadro: Dios, el rey y el Cid. Estas son las tres figuras de autoridad que

25 "Los infantes de Carrión son los personajes más codiciosos de todo el $C M C$, verdaderos polos opuestos a caballeros como Martín Antolínez o Minaya Álvar Fáñez” (Boix 2014: 35). 
ejercen legítimamente el poder, ya sea en su vertiente "hacer mal" legítimamente o proteger del mal, lo cual es otra cara por supuesto del poder. Se establece así, de manera implícita, una correlación entre estas tres instancias. Si bien la jerarquía entre ellas es evidente, Dios es todopoderoso, el rey es su vicario en la tierra, y el Cid es fiel vasallo del rey, cabe señalar que se incluye así al héroe en una terna claramente superior y aparte del resto de los personajes. Por otra parte, obsérvese que, por mucho que la posición del Campeador sea inferior a la de Dios y el rey, el héroe resulta ser el único personaje en ocupar las tres vertientes del poder, protección, violencia y diplomacia. Sin olvidar, por supuesto, que los infantes están ausentes de este cuadro, salvo como receptores fallidos de la diplomacia cidiana.

\subsection{Mal e identidad}

En los casos en los que el sustantivo "mal" tiene a los infantes de Carrión como protagonistas, se trata de un poder ilegítimamente ejercido, puesto que no se ejerce en el marco de la guerra, ni de la jerarquía sociopolítica, sino en el de la venganza privada, y sobre las indefensas hijas del Cid en el robledo de Corpes: "tanto mal comidieron los ifantes de Carrión" (2713). Tras este episodio, Pedro Vermúez y Álvar Fáñez se reúnen con las hijas del Cid y en sus palabras de consuelo se oyen ecos de reproches a los infantes:

Don Elvira e doña Sol, cuidado non ayedes

cuando vós sodes sanas y salvas e sin otro mal;

buen casamiento perdiestes, mejor podredes ganar

(2865-2867).

Hay que destacar que en el verso 2866, "mal" se refiere a daño físico, el ejercido por los infantes de Carrión sobre ellas. Es decir que el único mal que son capaces de hacer es un "mal hacer mal", frente al "buen hacer mal" del Cid. Por mucho que se jacten de ser "de natura" condes de Carrión, no son realmente poderosos, puesto que no pertenecen al sistema en el que el poder se ejerce de manera legítima ${ }^{26}$. No combaten militarmente a sus enemigos, ni participan en ninguna actividad diplomática.

Precisamente por ello, y este será mi último punto, son sustantivamente malos. Es decir que no hacen el mal, sino que son el mal. Son los únicos personajes de los que se dice que son "malos", en cinco ocasiones. La primera

26 "Nos de natura somos / de condes de Carrión" (2549): en otras cinco ocurrencias recurren los infantes a su alta cuna (en los versos 2554, 3275, 3296, 3394 y 3443. Sobre la oposición semántico-política entre "natura” y "esfuerço", véase Martin 1997: 196. 


\section{MARTA LACOMBA}

en boca de Avengalvón, cuando este descubre la traición de los infantes, que planeaban matarlo para despojarlo de sus bienes; se despide de ellos con estas palabras: "Aquí.m'e parto de vóscommo de malos e de traidores" (2681). La segunda, tercera y cuarta ocurrencias se encuentran en el episodio de las Cortes, que se terminan con los retos a los infantes. Tras haber revelado públicamente la cobardía de estos, Pero Vermúez formula su reto a Fernando: “'Riébtot” el cuerpo por malo e por traidor [...]!" (3343). Más adelante, Muño Gustioz hace lo mismo con Asur González: “¡Calla alevoso, malo e traidor [...]!” (3383) ${ }^{27}$. Aunque no será atendido por el rey, Minaya también reta a los infantes, profiriendo la acusación siguiente: "iRiébtoles los cuerpos por malos e por traidores!" (3442).

Tras los duelos, los hombres del Cid regresan a Valencia, quedando revelada y patente la infamia de los Infantes de Carrión, en la última y quinta ocurrencia en la que el "mal" se encarna en estos personajes:

$\begin{array}{ll}\text { A guisa de menbrados, } & \text { andan días e noches, } \\ \text { felos en Valencia } & \text { con mio Cid del Campeador, } \\ \text { por malos los dexaron } & \text { a los ifantes de Carrión }[. . .]\end{array}$
(3700-3702).

Malo, como sustantivo tiene un sentido claramente legal, con consecuencias jurídicas. Y de eso se va a tratar, de que la maldad de los infantes sea reconocida públicamente, de que se convierta, como reza la definición de sustantivo, de algo que tiene existencia real ${ }^{28}$. Esta maldad, este ser "malos", supone en efecto infamia, ya que "acarrea penas del menos valer, que consistían esencialmente en su exclusión de la corte, de toda actividad pública destacada y del trato social con otros nobles" (Montaner 1993: 314). Cabría pues decir que se trata de una suerte de destierro interior, o de muerte social. Como me lo hizo observar generosamente Érica Janin, la expresión “por malos los dexaron” (3702) remite fónicamente a la fórmula "por muertas las dexaron", que aparece varias veces en el $P M C$, referida a la afrenta de Corpes y que no puede no resonar al oído del lector. Se produce pues la asociación malos/muertos, que pasa por la etapa intermedia de la revelación pública de su maldad y la acusación de "menos

${ }^{27}$ Sobre la función de este personaje, véase Boix 2011.

28 Se produce un fenómeno de actualización y dramatización, semejante al que analiza y problematiza Soler Bistué (2007) en su estudio sobre el uso de los tiempos verbales en el PMC. 
valer". Y la exclusión de la corte por menos valer equivale a una muerte social. Lo moral, lo legal y lo existencial van aquí de la mano 29 .

A modo de conclusión, cabe señalar que se cierra el bucle que iba desde el inicio del $P M C$, desde la primera ocurrencia del adjetivo "malo" ("enemigos malos"), en el verso 9, hasta la sustantivación del término, “" "por malos los dejaron", en el 3702, en los últimos versos de la obra. De una maldad adjetiva y anónima, se pasa a su nominalización y sustantivación, los "malos y traidores", tienen cara, nombres y apellidos. Esta identificación equivale de hecho a una sentencia. El PMC se cierra en efecto sobre un proceso jurídico, y por lo tanto sobre la construcción y el establecimiento de una sentencia, de una verdad que se había ido revelando a lo largo de la obra.

Revelación que pasa, desde el punto de vista literario y discursivo, por un controlado manejo del lenguaje: de una maldad adjetiva, que expresa cualidad o accidente, si nos remitimos a la definición de adjetivo, se pasa a una maldad sustantiva, es decir efectiva y real. Lo soterrado y oculto se hace manifiesto. Se desvela así la relación entre el mal y el poder, entre el poder de hacer o no hacer mal. Al "hacer mal" legítimo del Cid se opone el hacer sufrir errático de los infantes de Carrión. Estos acaban encarnando el mal y la traición, pues no saben hacen bien el mal. Como se ha visto, se puede hacer mal, se debe incluso, en el caso de la guerra, o contra los enemigos declarados. El problema es que los infantes no entran en este marco, no son guerreros ni diplomáticos, sino parásitos. Son una plaga, de la que hay que deshacerse, pero nada más. En efecto, en el PMC, estamos muy lejos de un mal absoluto y contra el que parece que nada se puede hacer. Nombrando y descomponiendo el mal en males, el Cid vence frente a la miseria humana.

\section{Referencias bibliográficas}

Borx Jovaní, Alfonso, "La función de Asur González en el final del Cantar del mio Cid’. En: Vox Romanica, 70, 2011, pp. 244-252.

Boix Jovaní, Alfonso, "La generosidad en el Cantar de Mio Cid”. En: Dirāsāt Hispānicas, 1, 2014, pp. 27-42.

DEYERMOND, Alan, El Cantar de mio Cid y la épica medieval española. Barcelona: Sirmio, 1987.

DugGan, Joseph J., The "Cantar de Mio Cid": Poetic creation in its economical and social contexts. Cambridge: Cambridge University Press, 1989.

${ }^{29} \mathrm{Si}$ el mal resulta una variable discriminativa a la hora de analizar los personajes y de establecer una interpretación de la obra, algo parecido ocurre con la cuestión del "uso del dinero y las riquezas", que "sirve para caracterizar a los personajes", tanto en el plano individual como social (Boix 2014: 40). 
ELVIRA, Javier, "Sobre el origen de la locución concesiva por mucho que y similares". En: Alconchel, Girón; Iglesias Recuero, José Luis; Herrero, Silvia; Ruiz de Loizaga, Francisco Javier; Narbona, Antonio (coords.), Estudios ofrecidos al profesor José Jesús de Bustos Tovar. Madrid: Universidad Complutense, Servicio de Publicaciones, 2003, vol. 1, 2003, pp. 217-232.

JANIN, Érica, “Acerca del rol de Pedro Bermúdez en el Cantar de Mio Cid: Un acercamiento a su figura épica”. En: Olivar, 10, 2007, pp. 203-215.

MARTIN, Georges, "Le récit héroïque castillan (Formes, enjeux sémantiques et fonctions socio-culturelles)". En: Annexes des Cabiers de linguistique hispanique médiévale, 11, 1997, pp. 139-152.

MONTANER, Alberto, "Tal es la su auze: el héroe afortunado del Cantar de mio Cid'. En: Olivar: revista de literatura y cultura españolas, 10, 2007, pp. 89-105.

—, "Dichos y hechos: tácticas de la obediencia en el Cantar de mio Cid". En: Cahiers d'Études Hispaniques Médiévales, 34, 2011, pp. 29-39. (ed.), Cantar de mio Cid. Barcelona: Crítica, 1993.

Nuñez GonzÁlez, Elena, "El "otro" como ser diabólico: "Poema de mio Cid" y "Poema de Fernán González"”. Alicante: Biblioteca Virtual Miguel de Cervantes, 2004.

Pellen, René, Poema de mio Cid. En: Dictionnaire lemmatisé des formes et des références. Paris: Université de Paris XIII, 1979.

REAL ACADEMIA ESPAÑOLA, Diccionario de la lengua española, 23. ${ }^{\mathrm{e}} \mathrm{ed}$.

SMITH, Colin, Poema de mio Cid. Madrid: Cátedra, 1982.

Soler Bistué, Maximiliano, "Historia y ficción en el Poema de Mio Cid. Hacia un concepto de tiempo en la épica española". En: Olivar, 10, 2007, pp. 193 202.

ZERNOVA, Elena, "El epíteto como reflejo de la mentalidad medieval en el Poema de mio Cid’. En: Mata Induráin, Carlos; Morózova, Anna (eds.), Temas y formas hispánicas: arte, cultura y sociedad. Pamplona: Servicio de Publicaciones de la Universidad de Navarra, 2015, pp. 523-534. 